\title{
Bibliometric landscape of the researches on protein corona of nanoparticles
}

\author{
Zhengwei HUANG ${ }^{1 *}$, Fangqin $\mathrm{FU}^{1 *}$, Linjing WU ${ }^{1 *}$, Wenhao WANG ${ }^{2}$, Wenhua WANG ${ }^{2}$, Chaonan SHI ${ }^{1}$, \\ Ying HUANG $(\varangle)^{1}$, Xin PAN $(\varangle)^{2}$, and Chuanbin WU ${ }^{1}$ \\ 1 College of Pharmacy, Jinan University, Guangzhou 510006, China \\ 2 School of Pharmaceutical Sciences, Sun Yat-sen University, Guangzhou 510006, China
}

(C) Higher Education Press 2021

\begin{abstract}
Unclear biological fate hampers the clinical translation of nanoparticles for biomedical uses. In recent years, it is documented that the formation of protein corona upon nanoparticles is a critical factor leading to the ambiguous biological fate. Efforts have been made to explore the protein corona forming behaviors on nanoparticles, and rearrangement of the relevant studies will help to understand the current trend of such a topic. In this work, the publications about protein corona of nanoparticles in Science Citation Index Expanded database of Web of Science from 2007 to 2020 (1417 in total) were analyzed in detail, and the bibliometrics landscape of them was showcased. The basic bibliometrics characteristics were summarized to provide an overall understanding. Citation analysis was performed to scrutinize the peer interests of these papers. The research hotspots in the field were evaluated, based on which some feasible topics for future studies were proposed. In general, the results demonstrated that protein corona of nanoparticles was a prospective research area, and had attracted global research interests. It was believed that this work could comprehensively highlight the bibliometrics landscape, inspire further exploitation on protein corona of nanoparticles, and ultimately promote the clinical translation of nanoparticles.
\end{abstract}

KEYWORDS: protein corona; nanoparticle; bibliometrics; Web of Science

\section{Contents}

1 Introduction

2 Methods

2.1 Searching of literature

2.2 Bibliometrics analysis

2.3 Website and software operations

\subsubsection{Clarivate analytic}

Received August 5, 2021; accepted September 13, 2021

E-mails: huangy2007@jnu.edu.cn (Y.H.), panxin2@mail.sysu.edu.cn (X.P.)

* Z.H., F.F. and L.W. contributed equally to this work.

\subsubsection{VOSviewer \\ 2.3.3 HistCite \\ 2.3.4 SATI \\ 2.3.5 Bibliometric online platform \\ 2.3.6 Computer environment}

3 Results and discussion

3.1 Basic bibliometrics characteristics

3.2 Citation analysis

3.3 Hotspot mining

3.4 Possible fields under exploitation

4 Conclusions

Authors' contribution

Disclosure of potential conflict of interest 
Acknowledgement

References

Supplementary information

\section{Introduction}

Nanoparticles refer to the particulate systems with at least one nanoscale dimension [1], and are attracting attentions of scientists all over the world. Lipid-based [2], polymeric [3], metal [4] and silica [5] nanoparticles have been welldocumented, especially in the area of biomedicine and pharmaceutical sciences. The reported nanoparticles reveal enhanced therapeutic effects and/or mitigated system toxicities [6-8], creating new possibilities for the theranostics of diseases like tumors [9], diabetes [10] and neurodegeneration [11]. Seemingly, the clinical translation of nanoparticles embraces a bright future.

Regretfully, nanoparticles are moving towards the market with a slow pace. A major part of nanoparticles under laboratory research cannot achieve clinical translation. Literature shows that FDA approves less than 5 nanoparticles-related new drug applications per year in most time of the past decade [12]. As for those nanoparticles-related products already reached the market, there are only several ones widely demonstrating significant therapeutic effects: Abraxane ${ }^{\circledR}$ (paclitaxel-loaded albumin nanoparticles), Doxil ${ }^{\circledR}$ (doxorubicin-loaded liposomes) and Genexol-PM ${ }^{\circledR}$ (paclitaxel-loaded polymeric micelles) [13].

The insufficient understanding of the biological fate after administration is a critical hurdle for the clinical translation of nanoparticles. Without a clear knowledge in the biological fate on cell, tissue, organ and system level, the pharmacokinetics and pharmacodynamics profile of nanoparticles will not be clarified, which provokes the potential safety risk and doubtable therapeutic efficacy [14]. Worse still, the actual biological disposition of nanoparticles is generally quite different from the one revealed in in vitro studies, making it difficult to predict the in vivo fate [15]. It is vital to claim the biological fate of nanoparticles.

Recently, evidence accumulates that protein corona has a great impact on the biological fate of nanoparticles [1622]. Protein corona is a corona-like supramolecular structure formed around the surface of nanoparticles upon contact with biological fluids [23]. There are numerous types of proteins in biological fluids, which renders the composition of protein corona very complicated [24]. The formation of protein corona alters the surface chemistry of nanoparticles, i.e., change from the nanoparticulate coating layer into protein complex [25]. It is established that the surface chemistry of xenobiotics determines the cellular recognition and uptake processes [26]. Thus, protein corona will affect the cellular recognition and uptake of nanoparticles [27], and even the inflammatory [28] and cytotoxic pathways [29]. As to nanoparticles for drug delivery, premature cargo release may occur after protein corona formation [30]. The influence of protein corona can largely account for the failure of biological fate prediction.

The investigation on protein corona is necessary to interpret the biological fate of nanoparticles, and to finally promote the clinical translation. Since K. A. Dawson et al. proposed the concept of protein corona in 2007 [31], many efforts have been made in this region. The protein corona formation behaviors and mechanisms of lipid-based [32], polymeric [33], metal [34] silica [35] and other nanoparticles [36-38] have been comprehensively explored. With these works, relatively profound understanding of protein corona formation phenomenon is obtained.

Of note, the protein corona study should be continuously paid attention to. For one thing, because of the complex physiological environment, the interaction modes between coronated nanoparticles and cells are still unclear, limiting the interpretation of the in vivo evolution of protein corona. For another thing, nanoparticles prepared from new materials are emerging rapidly, and the previously established models cannot be directly applied to the new cases. Therefore, it is foreseen that protein corona will act as a research hotspot in the future.

In the present work, a bibliometric landscape of studies on protein corona of nanoparticles was illustrated. Specifically, basic bibliometric characteristics of the related papers were shown, and citation analysis and hotspots mining were performed. It is expected that this paper can provide an overall mastering of the relevant researches, analyze the current trend of studies, and inspire feasible topics for further investigations.

\section{Methods}

\subsection{Searching of literature}

Literature survey was finished at 11:00 a.m., April 21st, 2021 (UST +8$)$. With the search set of $($ TOPIC $=$ protein corona) and (TOPIC $=$ nanoparticle), the literature published in the time span of 2007-2020 were scanned in the 
Science Citation Index Expanded database that pertains to Web of Science Core Collection. The starting time 2007 was chosen because the first two papers about protein corona $[31,39]$ were published then.

\subsection{Bibliometrics analysis}

The duplicated and irrelevant results were removed, and the list of publications with full record and cited references information was exported. Subsequently, bibliometrics analyses were conducted via several tools including Clarivate Analytic (Philadelphia, PA) [40], VOSviewer (Leiden University, Netherlands) [41], HistCite (HistCite Software LLC, NY) [42], SATI [43] and bibliometric online platform [44].

\subsection{Website and software operations}

\subsubsection{Clarivate analytic}

After papers were retrieved from Web of Science Core Collection, the functions of 'analyze results' and 'create citation report' were utilized. The data rows were downloaded and visualized by Microsoft Office Excel (Microsoft Corporation, WA), Origin (OriginLab Corporation, MA) or GraphPad Prism (GraphPad Software, CA).

\subsubsection{VOSviewer}

Bibliographic data and text data were imported into VOSviewer, and maps were created. For bibliographic data, co-authorship with 'authors' and 'organizations' as unit of analysis was visualized. Also, the co-occurrence with 'keywords plus' as unit of analysis was illustrated, and the minimal occurrence number was set as 10. Bibliographic coupling was performed with 'documents' as unit of analysis. It was worth mentioning that only 1000 documents with the greatest connection strength were analyzed. For text data, title and abstract (structured abstract labels ignored) were extracted, and the minimum number of occurrences was set to 10 . The $60 \%$ most relevant terms were involved.

In all analyses, full counting was used, normalization method was association strength and clustering resolution was 1.

\subsubsection{HistCite}

The graph maker tool of HistCite was employed to visualize the cross-citation profile of retrieved documents.
In order to simplify the graph, the items of top 10 local citation score (LCS) counts were analyzed.

\subsubsection{SATI}

The exported full record and cited references information was compacted into a zip file, and uploaded to the online SATI system. The 'stem extraction' and 'smart cleanse' functions were activated, and the maximum size of matrix was 50 . The time series data were visualized by Microsoft Office Excel.

\subsubsection{Bibliometric online platform}

Through the platform, the publications were classified by region and year. Besides, the cooperation relationship between different regions was scrutinized.

\subsubsection{Computer environment}

The computer environment was Windows ${ }^{\circledR} 10$ operation system (x64, Microsoft Corporation, WA) installed with Java 8 (Oracle Corporation, CA) and Visual C ++2017 (Microsoft Corporation, WA).

\section{Results and discussion}

\subsection{Basic bibliometrics characteristics}

The literature survey returned 1417 papers. Of these papers, 514 were Open Access. In order to describe the overall feature of these papers and excavate their potential values, basic bibliometrics characteristics were summarized below.

The first two papers about protein corona of nanoparticles were published in 2007 [31,39], and since then the number of publications was raising gradually (Fig. 1(a)). After 2014, over 100 papers were published each year; more than 200 papers were published per year since 2019 . After plotting the number of publications versus year, a linear regression was conducted. The fitted formula was $y=$ $19.413 x-38987\left(R^{2}=0.9673\right)$. By this formula, it is estimated that 247 papers of this topic will be published in 2021, and will still increase after 2021. Overall, protein corona of nanoparticles was, is and will be attracting the interest in the scientific community.

In the 1417 papers, article, review and other types of documents accounted for $81.43 \%, 14.67 \%$ and $3.89 \%$, respectively (Fig. 1(b)). The majority of documents were 
(a)

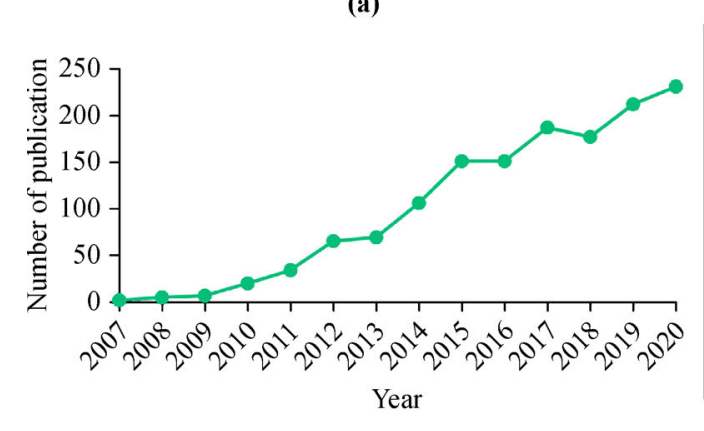

(c)

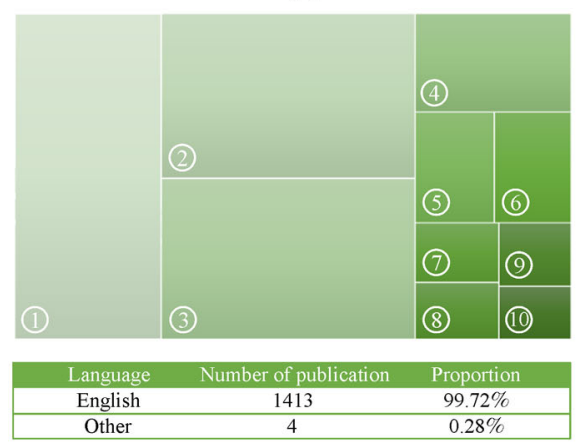

(b)

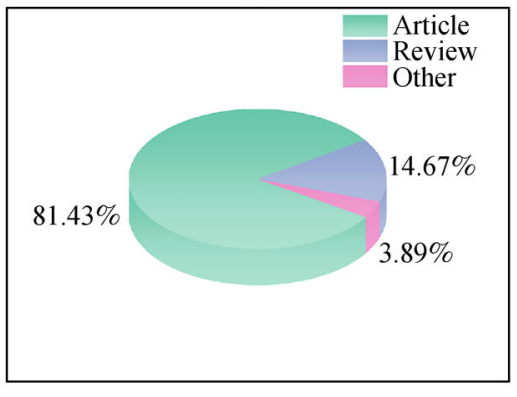

(d)

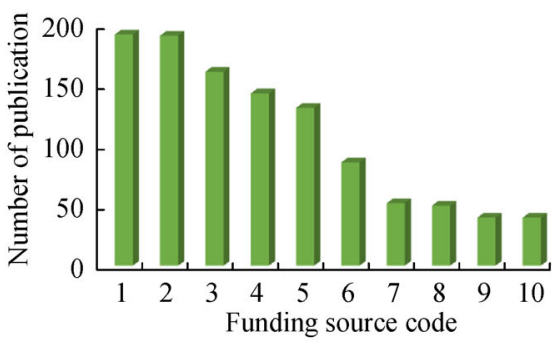

Fig. 1 (a) Number of publication versus year. (b) Type of documents. (c) Main research fields (upper panel: (1) chemistry; (2) materials science; (3) science \& technology: other topics; (4) physics; (5) biochemistry \& molecular biology; (6) pharmacology \& pharmacy; (7) toxicology; (8) biophysics; (9) engineering; (10) biotechnology \& applied microbiology) and language (lower panel). (d) Funding sources (1: United States Department of Health Human Services; 2: National Institutes of Health (NIH); 3: European Commission; 4: National Natural Science Foundation of China (NSFC); 5: National Science Foundation; 6: German Research Foundation; 7: NIH National Institute of Environmental Health Sciences; 8: NIH National Cancer Institute; 9: National Basic Research Program of China; 10: Science Foundation Ireland).

articles, and the percentage of reviews was considerable. The category 'other' mainly referred to meeting abstracts and news items, and claimed for a minority.

According to Fig. 1(c), the main research fields of the published papers included chemistry, material science, physics, biochemistry \& molecular biology, pharmacology \& pharmacy, toxicology, biophysics, engineering, biotechnology \& applied microbiology and the other topics of science and technology. The covered fields were concerned about the biomedical uses of nanoparticles, and thus were interest in the topic of protein corona.

Nearly 100\% of 1417 papers were in English, and only $0.28 \%$ of them (4 documents) were in other languages (Fig. 1(c), lower panel). Using English in writing would facilitate the international communication in the area.

Most of papers $(1243,87.72 \%)$ were granted by at least one funding. United States Department of Health Human Services, National Institutes of Health (NIH), European Commission, National Natural Science Foundation of China (NSFC) and National Science Foundation offered grants for more than 100 papers (Fig. 1(d)), and German
Research Foundation, NIH National Institute of Environmental Health Sciences, NIH National Cancer Institute and National Basic Research Program of China granted for more than 40 papers. These were the top-10 sources of funding. It was revealed that USA, China and the Europe paid much attention to the research about protein corona of nanoparticles.

There were 69 regions contributing to this topic, that is, 20.54 papers per region. The region-related information was displayed in Fig. 2. Classified by region and year, the distribution of publications was shown in Fig. 2(a). The first two papers in 2007 were from Ireland. In the period of five years (2007-2011), Germany, USA, Spain, UK, Italy, France, Canada and China also participated in the conversation. India jointed the discussion in 2012. There was a macroscopic trend that the numbers of publication from Italy, German, China and USA were growing with year.

Figure 2(b) depicted the regions with top-10 total number of publications. Over 450 papers were from USA, and more than 100 papers were contributed by 
(a)

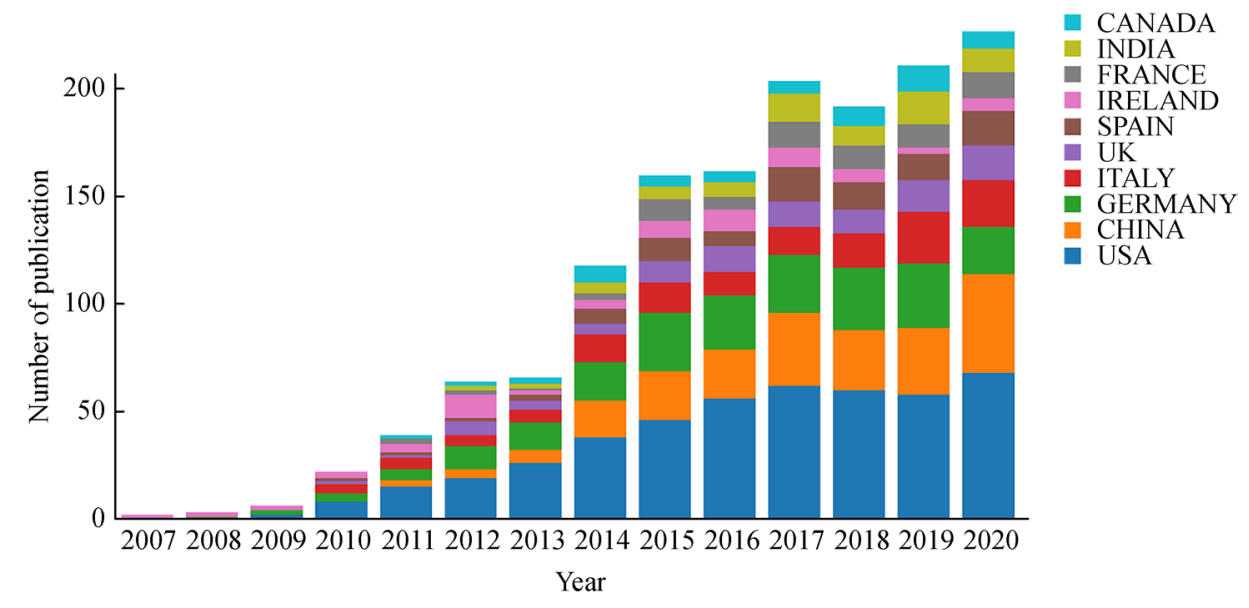

(b)

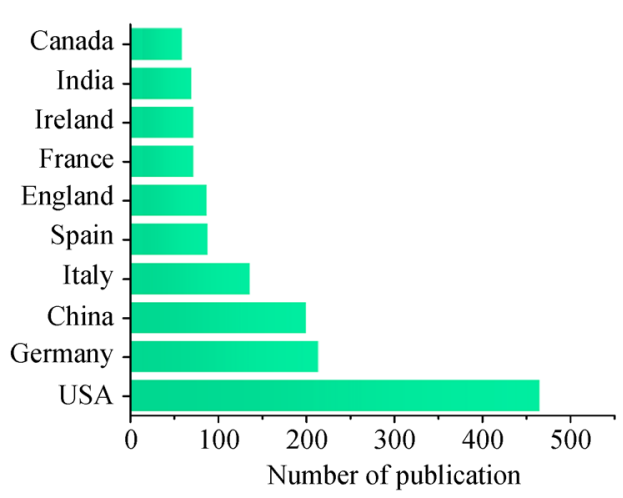

(c)

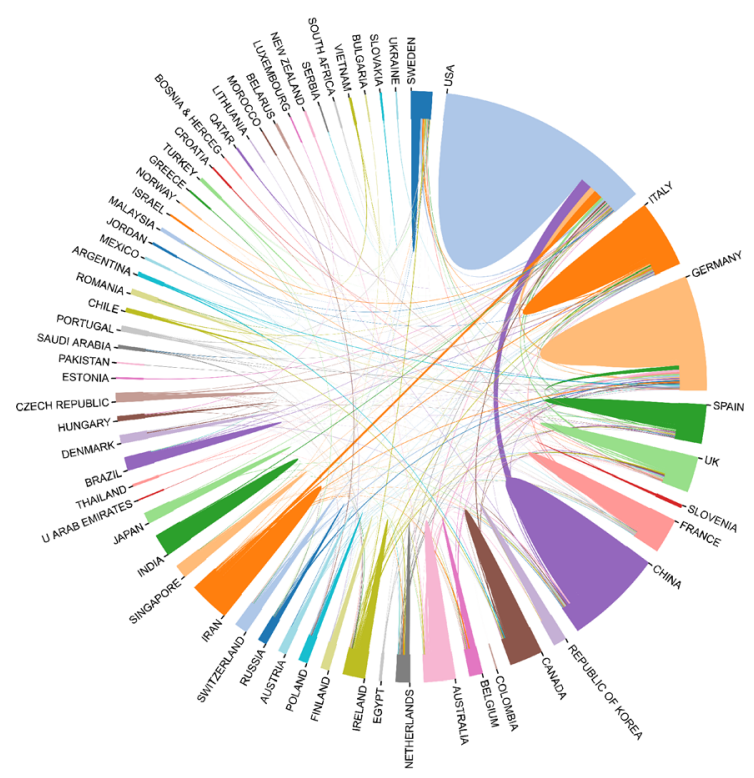

Fig. 2 (a) Number of publication from top-10 regions over time, stacked. (b) Number of publication from top-10 regions. (c) Cooperation links between regions.

Germany, China and Italy. Spain, England, France, Ireland, India and Canada credited for $50-100$ papers. This was basically in parallel with the results in Fig. 2(a). It could be perceived that these regions pay much attention to this field.

The cooperation relationship between different regions in the research on protein corona of nanoparticles was visualized in Fig. 2(c). The connecting curves represented the cooperation deeds, and the boldness of the curve was correlated to the cooperation times. Evidently, the cooperation was highly active in such a filed. China and USA shared a firm cooperation relationship in this topic. Also, Italy-USA, Iran-USA, Germany-USA and CzechItaly built strong cooperation relationship. It was anticipated that the cooperative investigation could effectively advance the understanding and application of protein corona.

The papers were published in 346 periodicals, or 4.10 papers per periodical. A word cloud of periodicals was provided in Fig. S1. The top-10 periodicals publishing the papers of interest were summarized in Fig. 3(a), ranking in the sequence of ACS Nano, Nanoscale, ACS Applied Materials \& Interfaces, Langmuir, Colloids and Surface B: Biointerfaces, Nanomedicine, Small, and International Journal of Nanomedicine, Nanotoxicology and Biomaterials. The above journals are all specific for the field of nanoscience and nanotechnology, especially focused on the biomedical, pharmaceutical and toxicological aspects, which was in parallel with the main research fields in Fig. 1(c). The top-5 periodicals published more than 30 
(a)

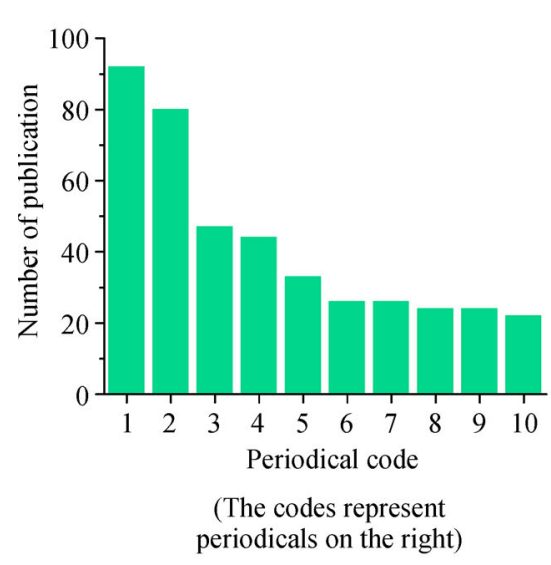

(b)

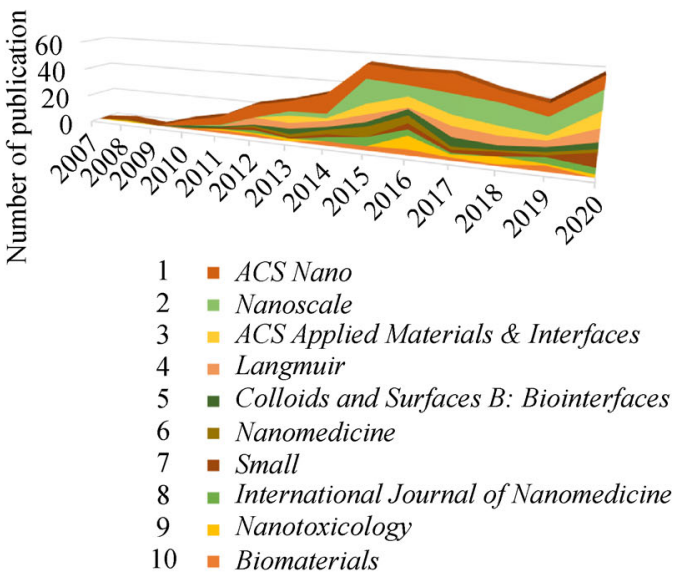

Fig. 3 (a) Number of publication in top-10 periodicals. (b) Time evolution of number of publication in top-10 periodicals, stacked.

papers, and the 5 th-10th periodicals published about 20 papers. The papers published in the top-10 periodicals only accounted for $29.50 \%$ out of 1417 , indicating a relatively homogenous distribution in all periodicals. Further, it could be inferred that such a topic had arouse broad interests from various periodicals, which was in turn favorable for the relevant fundamental studies.

The time evolution of the number of publication in top10 periodicals was depicted in Fig. 3(b). The number of publication before 2010 was neglectable (only 1 paper was published in Langmuir in 2008), which was in accordance with the overall time distribution profile in Fig. 1(a). Biomaterials, ACS Applied Materials \& Interfaces, Nanoscale and ACS Nano published 4, 2, 1 and 1 paper in 2010, respectively. Since then, the number of publication ascended. It should be mentioned that the first two papers in 2007 were published in Proceedings of the National Academy of Sciences of the United States of America [31] and Advances in Colloid and Interface Science [39], whilst they were not listed in the top-10 periodicals.

It should be noted that 1544 institutions contributed in the area, and the number of institutions was even more than the number of publications (1417). Accordingly, it was speculated that a significant proportion of papers were the products of inter-institution cooperation. Please refer to Fig. S2 for the word cloud of institutions. The top-10 contributing institutions were shown in Figs. 4(a) and 4(b). Chinese Academy of Sciences contributed the highest number of publications (63) in this field. Institutions in USA, like University of Illinois, University of California and Harvard University, appeared in the top-10 list. Besides, institutions in Ireland (University College Dublin), France (Centre National De La Recherche
Scientifique), Germany (Helmholtz Association and Johannes Gutenberg University of Mainz) and Italy (Sapienza University of Rome) were also included. These institutions located in China, USA, Ireland, France, Germany and Italy, whose positions had been recorded in Fig. 2(b) (top-10 regions).

The cooperation linkage of the top- 1 institution, i.e., Chinese Academy of Sciences, was visualized in Fig. 4(b). There were intense cooperation bonds between Chinese Academy of Sciences and University of Chinese Academy of Sciences or National Center for Nanoscience \& Technology, China, two institutions with strong nanoresearch background in China. It established cooperation relationship with many other Chinses institutions as well, e.g., Shandong University, Anhui University and Chongqing Medical University. International cooperation was conducted between Chinese Academy of Sciences and Columbia University, University of Hawaii at Monoa, Mahidol University, etc. From this example, it could be seen that the inter-institution collaboration was quite active. Because each institution had unique strength in nanoscience research, the collaboration between institutions facilitated the interaction of the newest knowledge of protein corona.

The 1417 papers were authored by 6294 researchers. In average, there were 4.44 researchers in the authorlist of one paper. Co-authorship was a common phenomenon in the protein corona studies, and it would be beneficial for the integration of academic viewpoints of authors. Figure S3 showed the word cloud of authors. The time evolution profile of top-10 authors with the highest number of publications was illustrated in Fig. 5(a). For the first time in 2007, K. A. Dawson, I. Lynch and T. Cedervall cooperated 
(a)
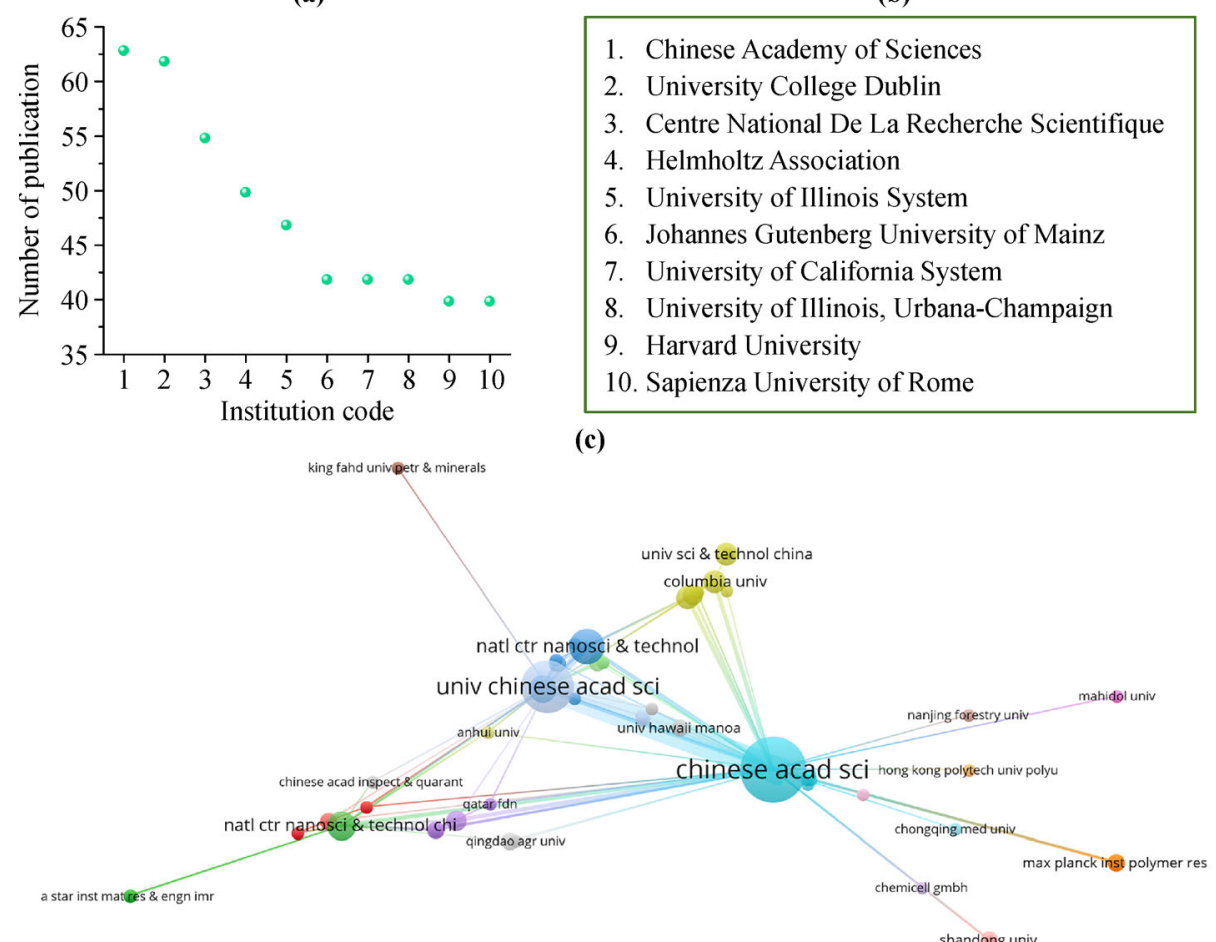

(b)

1. Chinese Academy of Sciences

2. University College Dublin

3. Centre National De La Recherche Scientifique

4. Helmholtz Association

5. University of Illinois System

6. Johannes Gutenberg University of Mainz

7. University of California System

8. University of Illinois, Urbana-Champaign

9. Harvard University

10. Sapienza University of Rome

(c)

shandong univ

Fig. 4 (a) Number of publication in top-10 institutions. (b) Assignment of codes in (a). (c) Cooperation linkage of the top-1 institution.

with each other and published two papers, viz. those published in Proceedings of the National Academy of Sciences of the United States of America [31] and Advances in Colloid and Interface Science [39]. A. Salvati [45] and W. J. Parak [46] separately authored their first paper in 2009. Subsequently, G. Caracciolo, D. Pozzi and K. Landfester published their first papers in 2010. M. Mahmoudi and C. Chen joined the community afterwards.

Taking K. A. Dawson, the top- 1 author for instance, the cooperation linkage was shown in Fig. 5. K. A. Dawson is from University College Dublin in Ireland (top-2 institution in Figs. 4(a) and 4(b)), who co-authored with the researchers from the same institution (like I. Lynchi, in green circle), other institutions in Ireland (like L. Rocks from Science Foundation Ireland, in red circle), institutions in other regions of Europe (like T. Cederval from Lund University in Sweden, in green circle), and institutions in other continents (like A. S. Pitek from Case Western Reserve University in USA, in green circle but not literally marked). As the pioneer and the most 'fruitful' researcher in this field, K. A. Dawson established intense collaborative tiles with other investigators. For emerging investigators, it was advisable to learn the research mode of $\mathrm{K}$. A. Dawson delicately.
The basic bibliometric characteristics of the publications about protein corona of nanoparticles had been elaborated. In summary, the related interests were growing in a large number of institutions and periodicals all over the world, and the cooperation in the frontier was very active. It was expected that more creative works in such a field would be published in the future.

\subsection{Citation analysis}

Furthermore, citation analysis of the retrieved 1417 papers was performed, so as to understand the secondary exploitation situations of these publications, and to clarify what insight they provided for the scientific community.

The primary papers were cited for 63558 times by 27814 secondary papers within 2007-2020. Averagely, one primary paper was cited for 44.85 times by 19.63 secondary papers, with an $H$-index of 110 . This meant that 110 out of 1417 papers were cited for at least 110 times. Basic bibliometrics attributes of the secondary papers were summarized in Fig. 6 .

The number of cited publications and times cited over year was demonstrated in Fig. 6(a). The primary papers were cited for 11 times by 11 secondary papers in 2007 . From 2008 on, times cited was greater than the number of 
(a)

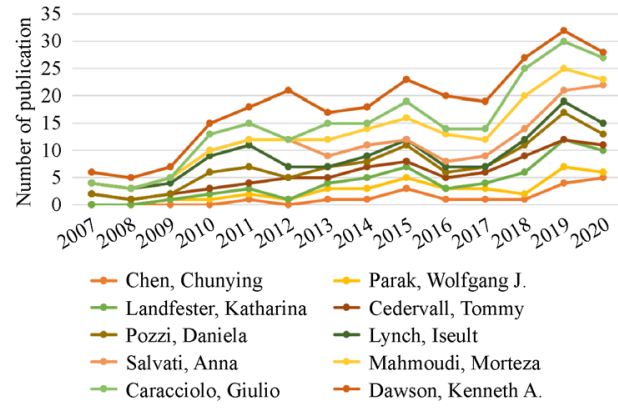

(b)

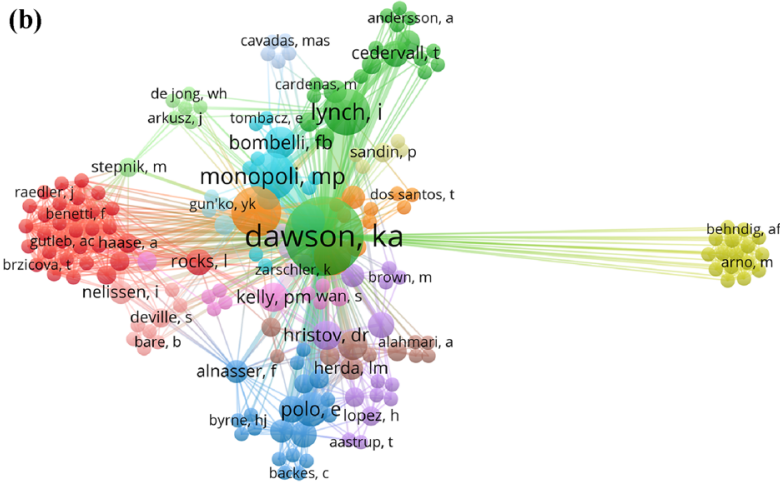

Fig. 5 (a) Time evolution of number of publication by top-10 authors, stacked. (b) Cooperation linkage of the top-1 author.

cited publications, and both of them increased moderately. Since 2012, substantial increment had been witnessed each year. More citations were anticipated in 2021 and the upcoming years.

According to Fig. 6(b), $77.22 \%, 19.08 \%$ and $3.70 \%$ of the secondary papers were in the forms of article, review and other types, respectively. The major part was still article, but compared to the situation of the primary papers (81.43\%, Fig. 1(b)), the percentage dropped slightly; the proportion of review increased from $14.67 \%$ to $19.08 \%$, indicating that the discussion of protein corona phenomenon was involved in the reviews with other topics.

The top-10 research fields of the secondary papers included chemistry, materials science, physics, pharmacology \& pharmacy, biochemistry \& molecular biology, engineering, toxicology, environmental science \& ecology, polymer science and the other topics of science and technology (Fig. 6(c), upper panel). The major fields were identical with those of the primary papers, but biophysics and biotechnology \& applied microbiology were replaced by environmental science $\&$ ecology and polymer science in the list. This indicated that the investigators of environmental and polymer science realized the potential impact of protein corona in the corresponding fields. Protein-coronated nanomaterials in the environment might threaten the human health [47], and the formation of protein corona could influence the biopolymer functions [48]. Therefore, such a topic deserved the interests from those two fields.

The distribution of language (Fig. 6(c), lower panel) was similar to that of the primary papers, i.e., $>99 \%$ in English and $<1 \%$ in other languages. This would favor the international discussion about the related topics.

The secondary papers were financially supported by 24290 sources. Seen from Fig. 6(d), NSFC supported 5266 secondary papers, accounting for $18.93 \%$, which was a significant proportion. Top- 2 to top-5 and top- 6 to top- 10 sources supported more than 1000 and 500 secondary papers, respectively. The top-10 sources were in China, USA and Europe.

Figure 6(e) depicted the top-10 contributing regions. In the scenario of the primary papers, USA contributed the highest number of publication (Fig. 2(b)). Herein, China with approximately 7000 hits ranked in the first place, exceeding USA. It was associated with the strong support from NSFC. In addition, Germany, Italy, India, England, France and Spain appeared in both lists, and Republic of Korea and Australia were newly added into Fig. 6(e).

The main publication media for the secondary papers were displayed in Fig. 6(f): Nanoscale, ACS Nano, ACS Applied Materials \& Interfaces, Langmuir, RSC Advances, International Journal of Nanomedicine, Colloids and Surface B: Biointerfaces, Scientific Reports, Small and Journal of Controlled Release. However, RSC Advances, Scientific Reports and Journal of Controlled Release were not listed in Fig. 3(a), top-10 periodicals of the primary papers. The top- 5 periodicals each published more than 500 papers, and top- 6 to top- 10 periodicals published over 300 papers. In total, they published 5113 papers, or $18.38 \%$ of 27814. The percentage was even lower than that of the primary papers $(29.50 \%)$, suggesting a highly homogeneous distribution of secondary papers in all periodicals.

As for the contributing institutions, Chinese Academy of Sciences, Centre National De La Recherche Scientifique, University of California, Harvard University and Helmholtz Association ranked in the top 10, in parallel with the situation of the primary papers. Chinese Academy of Sciences contributed 1428 papers, which was significantly more than other institutions ( $<900$ papers).

There was a relatively high degree of similarity in the basic bibliometric properties between the primary papers and the secondary papers, in terms of document type, research field, language, contributing region, periodicals, 
(a)

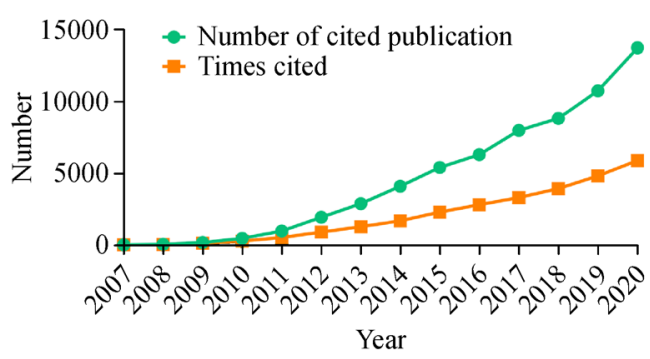

(c)

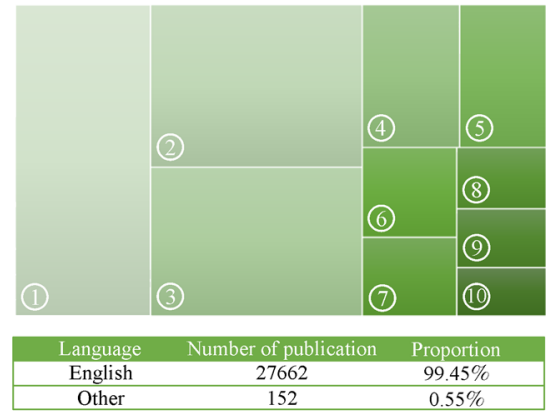

(e)

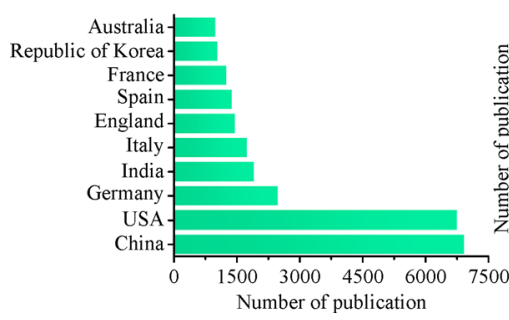

(f)

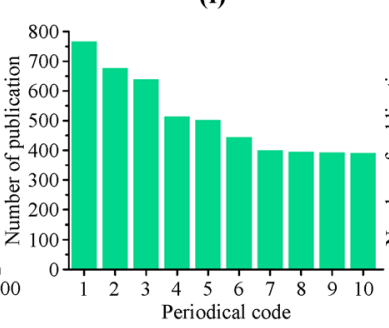

(b)

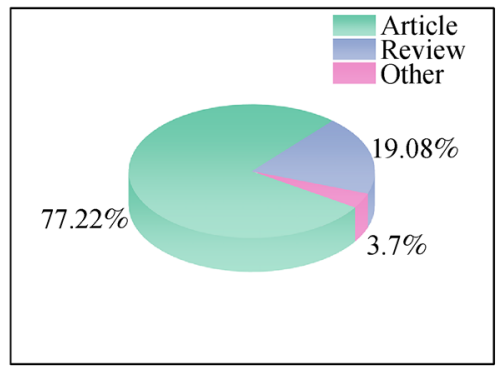

(d)

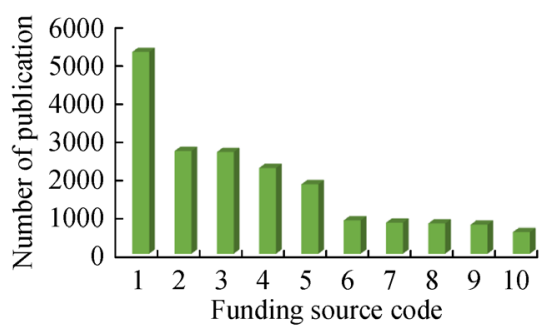

(g)

Fig. 6 (a) Number of cited publication and times cited versus year. (b) Type of documents. (c) Main research fields (upper panel: (1) chemistry; (2) materials science; (3) science \& technology: other topics; (4) physics; (5) pharmacology \& pharmacy; (6) biochemistry \& molecular biology; (7) engineering; (8) toxicology; (9) environmental sciences \& ecology; (10) polymer science) and language (lower panel). (d) Funding sources (1: National Natural Science Foundation of China (NSFC); 2: United States Department of Health Human Services; 3: National Institutes of Health (NIH); 4: European Commission; 5: National Science Foundation; 6: German Research Foundation; 7: NIH National Cancer Institute; 8: National Basic Research Program of China; 9: Fundamental Research Funds for The Central Universities; 10: UK Research Innovation). (e) Number of publication from top-10 regions. (f) Number of publication in top-10 periodicals (1: Nanoscale; 2: ACS Nano; 3: ACS Applied Materials \& Interfaces; 4: Langmuir; 5: RSC Advances; 6: International Journal of Nanomedicine; 7: Colloids and Surface B: Biointerfaces; 8: Scientific Reports; 9: Small; 10: Journal of Controlled Release). (g) Number of publication from top-10 institutions (1: Chinese Academy of Sciences; 2: Centre National De La Recherche Scientifique; 3: University of California System; 4: University of Chinese Academy of Sciences; 5: Harvard University; 6: Helmholtz Association; 7: Consejo Superior De Investigaciones Cientificas; 8: Consiglio Nazionale Delle Ricerche; 9: CNRS Institute of Chemistry Inc.; 10: Sichuan University).

etc. An evident difference was that investigators in China show the greatest interest in citing the works about protein corona of nanoparticles, although the number of publication they contributed only ranked in the third place. This could be explained as the growing concern on such a topic, and maybe more interesting works would be reported by China.

In order to showcase the citation circumstances of the primary papers, the top-10 most cited ones of which were extracted, shown in Table 1 [31,49-57].
All papers were published in 2013 or earlier, and could be viewed as the pioneering researches in the field. They were published in the important periodicals of chemistry and material sciences. Among them, Nos. 1, 2, 4, 5, 8, 9 and 10 were articles, and Nos. 3, 6 and 7 were reviews. The numbers of citing publication of the 10 papers were illustrated in Fig. 7(a).

As the first paper systemically reporting protein corona phenomenon, the No. 1 paper was cited in 2007, the same year of publication. Nos. 4, 5, 6, 7, 8, 9 and 10 also 


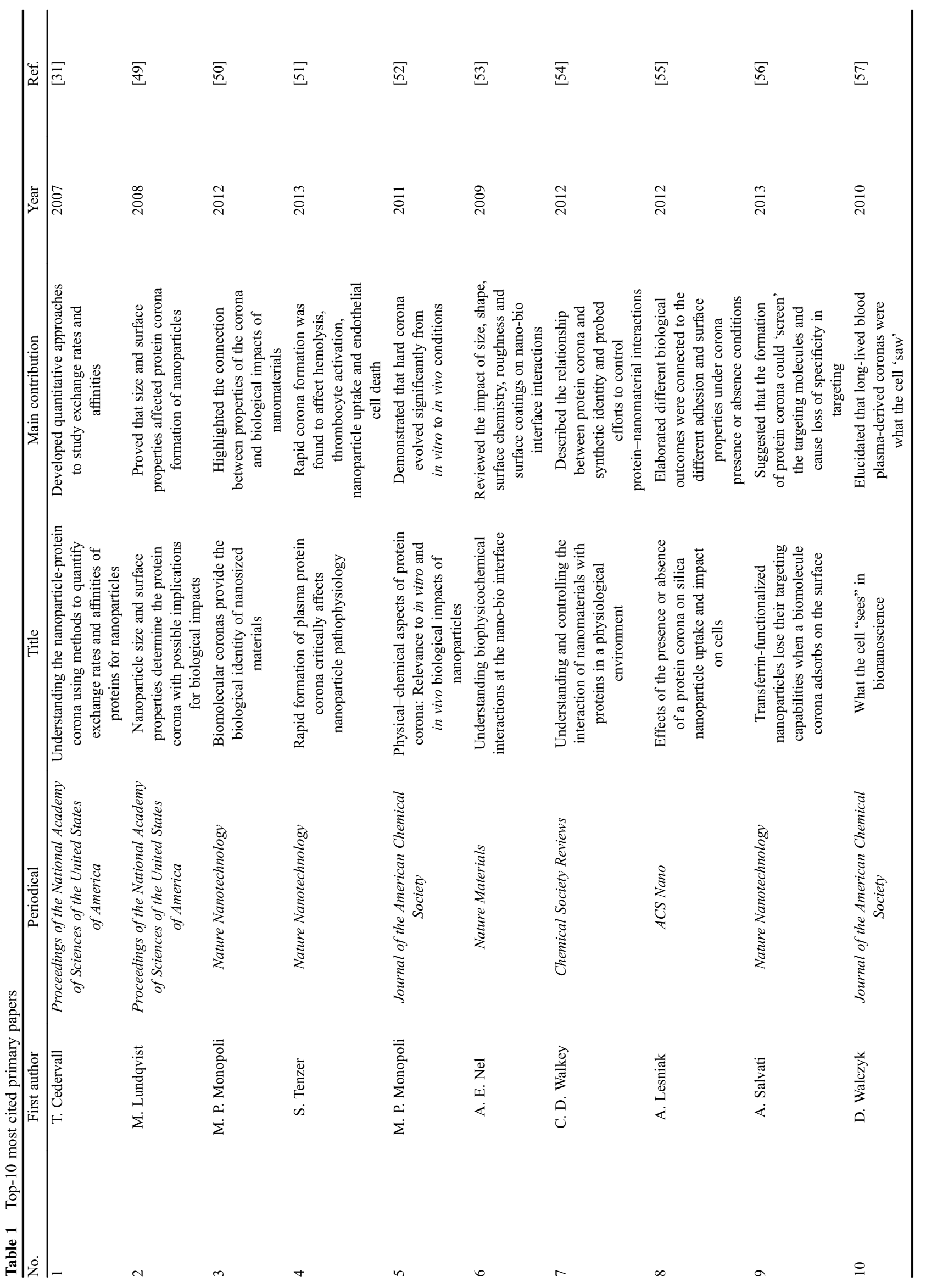


(a)

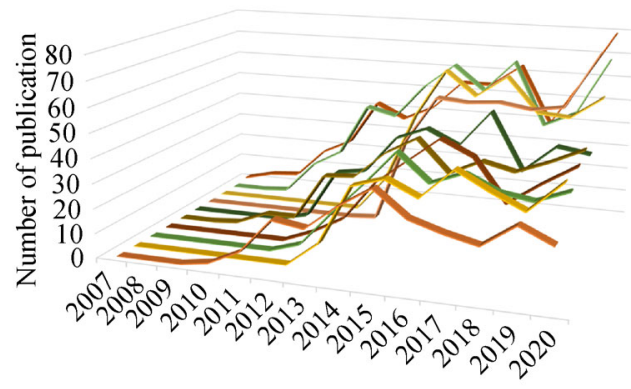

$-10=9-8=7-6=5-4=3-2=1$

(b)

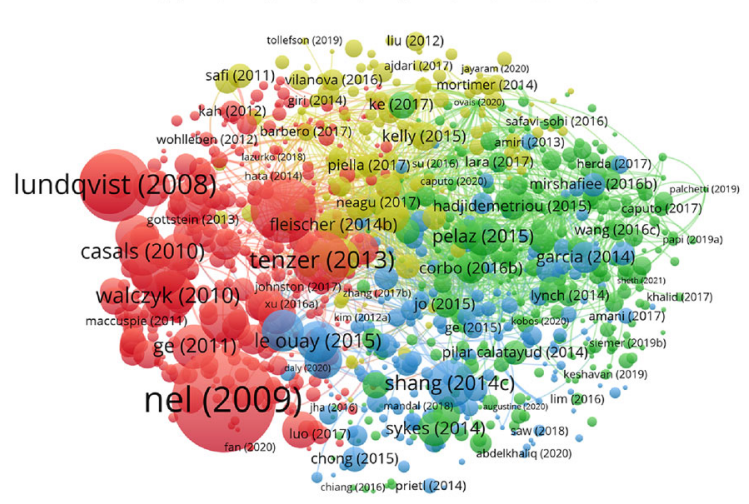

Fig. 7 (a) Time evolution of number of cited publications of primary papers. (b) The code $1-10$ referred to the top-10 most cited primary papers listed in Table 1; bibliographic coupling visualization.

welcomed their first citation in the published year. Nos. 2 and 3 were published in September and December, respectively, and consequently received the first citation in the second year. It was demonstrated that these papers provoked prompt discussions and inspired follow-up studies. After the first citation, the number of citing publications raised, fluctuated, and roughly reached a plateau in 2016-2020. Of note, a significant increment was observed in 2020 for Nos. 1, 2 and 4. These papers might continue to motivate new exploitations in the field.

For outlining the papers mostly representing the research front, bibliographic coupling profiles of the 1417 primary papers were illustrated (Fig. 7(b)). It was documented that bibliographic coupling worked by linking two documents that referenced the identical set of cited third documents, and documents were clustered by the co-citing behaviors [58]. Four clusters were obtained for the 1000 documents with strongest connections, marked in red (370 documents), green (295 documents), blue (178 documents) and yellow (157 documents), respectively. Isolated circles in Fig. 7(b) meant no coupling with other documents.

The results of bibliographic coupling were indicators of the similarities in topics between documents [59]. High degrees of topic similarities were shown in Fig. 7(b). For instance, Nos. 2, 4, 6 and 10 papers from Table 1 exhibited great coupling in red cluster. As the pioneering researches, they might share similar references that inspired the protein corona investigations.

By far, it was elucidated that citations were accumulating along with time for the 1417 primary papers, and an intense bibliographic coupling was revealed. Some peripheral citation analysis data were shown in Fig. S4.

\subsection{Hotspot mining}

Having understood the basic bibliometrics characteristics and citation status, it was advisable to mine the research hotspots in the field to put forward new orientations for the studies on protein corona of nanoparticles.

Analysis on keywords might be a useful approach for hotspot mining. The keywords in 1417 papers were screened (a word cloud of which was displayed in Fig. $\mathrm{S} 5)$, the top-10 high-frequency ones were refined, and their time evolution was depicted in Fig. 8(a). 'Protein corona', 'nanoparticle', 'gold nanoparticle', 'nanomedicine', 'drug delivery', 'cytotoxicity', 'cellular uptake', 'silver nanoparticle', 'nanotoxicology' and 'protein adsorption' were the keywords with highest frequency.

However, since the topic per se was 'protein corona of nanoparticles', the keywords 'protein corona', 'nanoparticle' and 'nanomedicine' could not provide further information. With these null keywords filtered, a new top-10 list was obtained: 'gold nanoparticle', 'drug delivery', 'cytotoxicity', 'cellular uptake', 'silver nanoparticle', 'nanotoxicology', 'protein adsorption', 'proteomics', 'macrophage' and 'magnetic nanoparticle'. These keywords could be classified into four groups: (1) 'Gold nanoparticle', 'silver nanoparticle' and 'magnetic nanoparticle': main subjects; (2) 'Drug delivery' and 'nanotoxicology': research categories; (3) 'Cytotoxicity', 'cellular uptake' and 'macrophage': physiological aspects; (4) 'Protein adsorption' and 'proteomics': methodologies. It was inferred that the type of nanoparticles, characterization methods, impacts on physiological pathways and implications for other disciplines were the focuses of most studies.

The associated time evolution profile was shown in Fig. 8(b), and basically the curves were fluctuating with time. The researches involving these keywords were published each year, while it was difficult to judge the evolving tendency of the keywords.

The average time overlay profile of keywords was visualized in Fig. 8(c) (the corresponding density visualization was provided in Fig. S6). The keywords were 
(a)

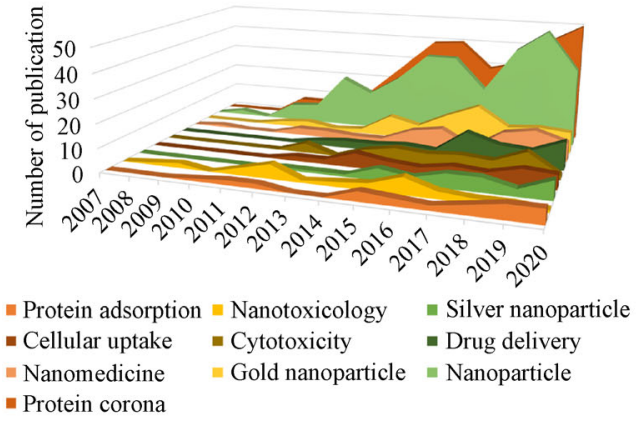

(b)

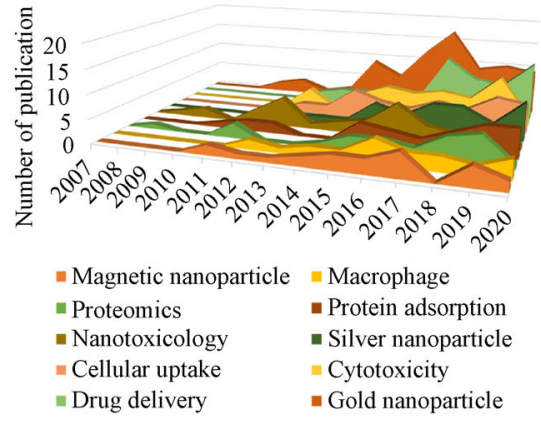

(c)

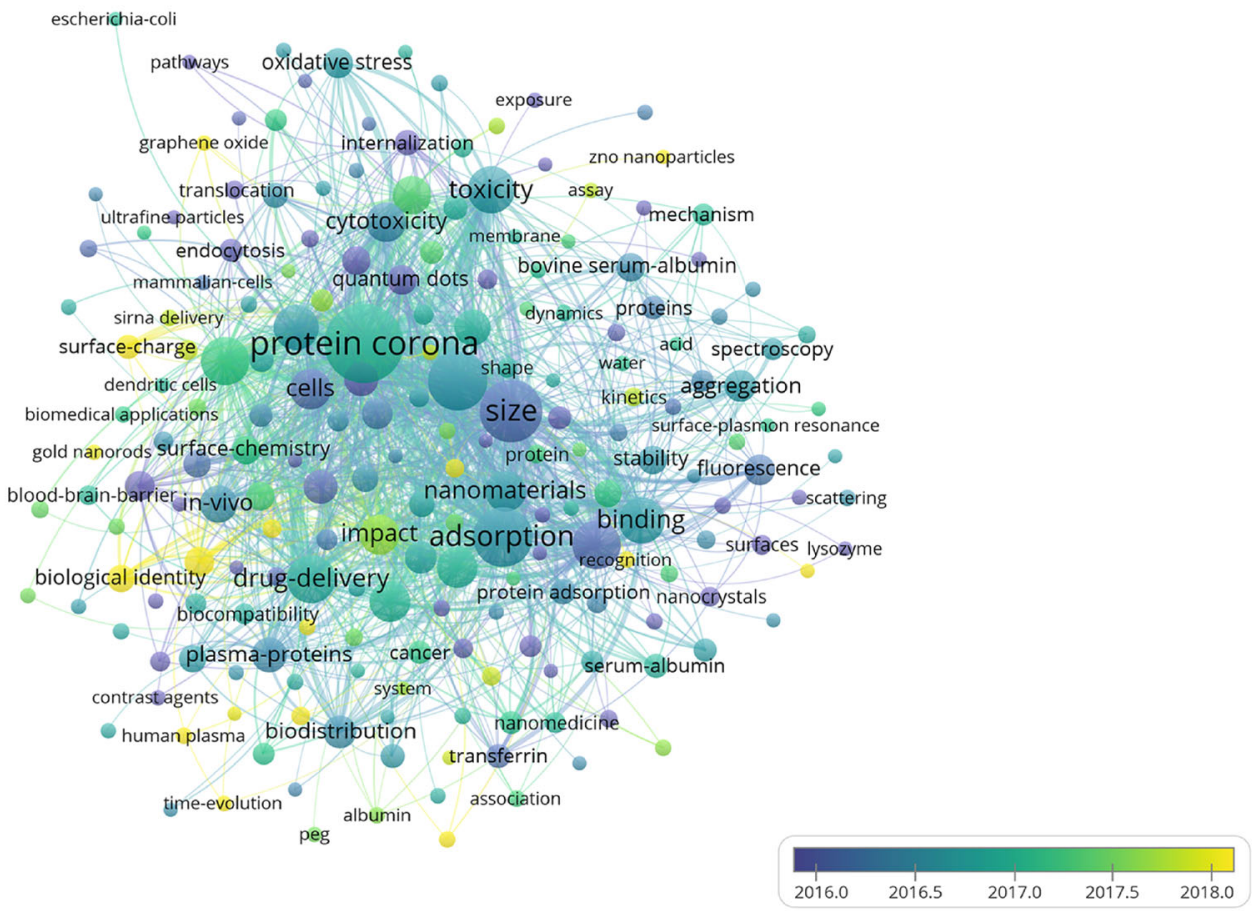

Fig. 8 (a) Time evolution of number of top-10 keywords, unfiltered. (b) Time evolution of number of top-10 keywords, filtered. (c) Average time overlay visualization of keywords.

marked in blue-green-yellow gradients, and blue and yellow represent an early and late published year, respectively. It was found that most keywords were in blue or green color, suggesting an early published year. For example, 'cells' and 'internalization' were in blue, which indicated that the effect of protein corona on cell internalization of nanoparticles had been intensively reported in the earliest stage. 'Drug delivery' and 'cancer' were in green, implying that the manipulation of protein corona for drug delivery and cancer treatment was documented in the early phase. 'PEG (polyethylene glycol)' and 'siRNA (small interfering ribonucleic acid) delivery' were in pale green, which meant that the
PEGylation of nanomaterials for the shielding of protein corona, and the application of protein corona in siRNA delivery were relatively new topics. 'Recognition' and 'graphene oxide' were in yellow, and thus the influence of protein corona of molecular recognition process of nanosized xenobiotics and the protein corona forming mechanisms of newly-developed nanomaterials like graphene oxide were the recent emphases.

Hotspots of studies on protein corona of nanoparticles were partly analyzed using keywords, but keywords did not convey the full emphases of a paper. For a more accurate mining, all terms in the documents should be taken into consideration. To this end, average time overlay and 
density visualization of co-occurred terms (60\% most relevant ones) were conducted, illustrated in Figs. 9(a) and $9(\mathrm{~b})$.

(a)

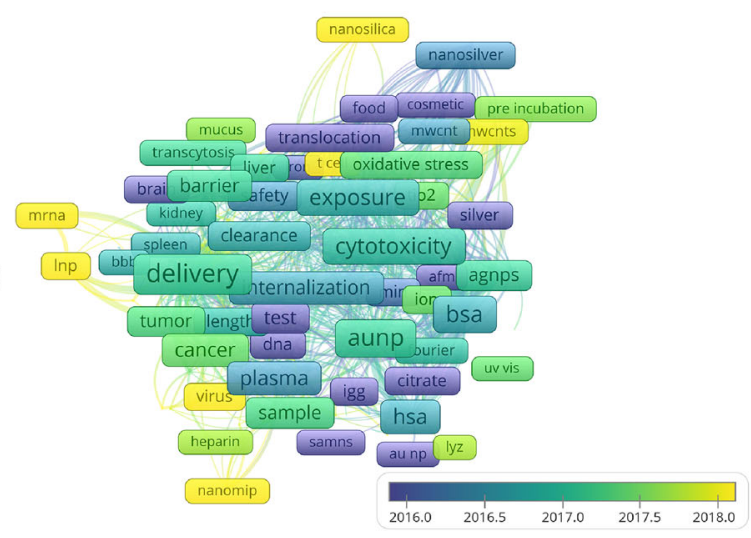

(b)

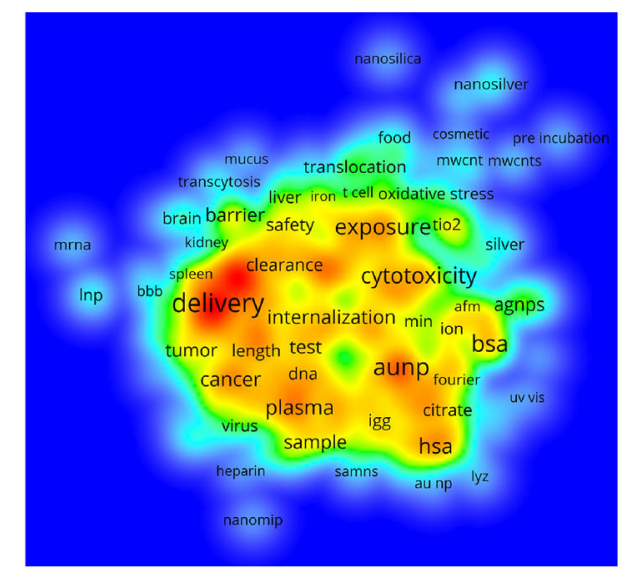

Fig. 9 (a) Average time overlay visualization of terms. (b) Density visualization of terms.

Similar to the results in Fig. 8, the terms 'nanosilver', 'internalization', etc. were mostly mentioned in the early years, and the terms 'delivery' and 'cancer' were used more recently. It should be mentioned that Fig. 9 revealed several new focuses marked in yellow: Nanosilica, MWCNTs (multi-walled carbon nanotubes), T cells, mRNA (messenger ribonucleic acid), LNP (lipid nanoparticles), virus (representing virus-like nanoparticles) and nanoMIP (molecularly imprinted polymers). Among them, MWCNT referred to carbon nanotubes with multi-wall structure, which was a one-dimension nanomaterial of ultrahigh strength; nanoMIP was a nanotechnology employing molecular imprinting techniques in biorecognition, exhibiting ample potentials in targeted therapy. These terms could be categorized into two parts: (1) Nanosilica, MWCNTs, LNP, virus and nanoMIP. They were associated with the protein corona studies on new patterns of nanoparticles. (2) T cells and mRNA. They reflexed the investigation upon the cellular/molecular level fates of coronated-nanoparticles.

To sum up, the hotspots of studies on protein corona of nanoparticles included the impact of protein corona formation on the biological fate of nanoparticles, and the protein corona forming behaviors of innovative nanomaterials.

\subsection{Possible fields under exploitation}

Based on the above discussion, it could be envisioned that the field of protein corona of nanoparticles deserved exploitation. Here, the authors recommended several possible fields pending investigation:

(1) Subcellular and molecular level biological fate of coronated nanoparticles. This would help to give a clearer manifestation of in vivo fate, and promote the clinical translation of nanoparticulate drug delivery systems.

(2) Protein corona forming mechanisms of nanoparticles with clinical translation potentials (like cubosomes [60]). These nanoparticles had demonstrated the feasibility as drug carriers, and the clarification of their protein corona formation behaviors would be very beneficial for clinical translation.

(3) Artificial protein corona for the design of novel nanosystem. Preincubation with a certain protein to form an artificial protein corona could endow nanoparticles with new functions (like an artificial apolipoprotein E4 corona enabled brain targeting [61]), which might stimulate new ideas in nanomaterials design.

\section{Conclusions}

In this paper, the bibliometrics landscape of the researches on protein corona of nanoparticles was illustrated in detail. Firstly, the basic bibliometrics characteristics were assessed, and the results showed that this topic arouse increasing interests across the world. International collaboration in it was highly active. Secondly, citation analysis of the primary papers was launched, and interestingly the secondary papers possessed similar bibliometrics characteristics with the primary ones. Besides, the bibliographic coupling phenomenon was quite evident. Thirdly, hotspot mining was realized through the analysis of high-frequency keywords and terms. It was revealed that claiming biological fate on cellular and molecular level after protein corona formation and the forming mechanisms of protein corona on newly synthesized nanomaterials were the major 
hotspots. Overall, this work provided a whole picture of protein corona studies from a bibliometrics perspective.

Authors' contribution Zhengwei Huang: bibliometric analysis and manuscript writing; Fangqin Fu: database searching, tables and illustration preparation; Linjing Wu: data washing, screening and processing; Wenhao Wang, Wenhua Wang and Chaonan Shi: software, file assorting and manuscript formatting; Ying Huang and Xin Pan: conceptualization, funding acquisition and manuscript polishing; Chuanbin Wu: supervision and proofreading.

Disclosure of potential conflict of interest The authors declare no conflict of interest.

Acknowledgement This work was supported by the National Natural Science Foundation of China under Grant No. 82073774.

\section{References}

[1] Flauraud V, Mastrangeli M, Bernasconi G D, et al. Nanoscale topographical control of capillary assembly of nanoparticles. Nature Nanotechnology, 2017, 12(1): 73-80

[2] Pavlov R V, Gaynanova G A, Kuznetsova D A, et al. Biomedical potentialities of cationic geminis as modulating agents of liposome in drug delivery across biological barriers and cellular uptake. International Journal of Pharmaceutics, 2020, 587: 119640

[3] He H, Xie Y, Lv Y, et al. Bioimaging of intact polycaprolactone nanoparticles using aggregation-caused quenching probes: Sizedependent translocation via oral delivery. Advanced Healthcare Materials, 2018, 7(22): 1800711

[4] Li Y, Chen W, Qi Y, et al. $\mathrm{H}_{2} \mathrm{~S}$-scavenged and activated iron oxide-hydroxide nanospindles for MRI-guided photothermal therapy and ferroptosis in colon cancer. Small, 2020, 16(37): 2001356

[5] Wang S, Li F, Qiao R, et al. Arginine-rich manganese silicate nanobubbles as a ferroptosis-inducing agent for tumor-targeted theranostics. ACS Nano, 2018, 12(12): 12380-12392

[6] Zelepukin I V, Popov A A, Shipunova V O, et al. Lasersynthesized TiN nanoparticles for biomedical applications: Evaluation of safety, biodistribution and pharmacokinetics. Materials Science and Engineering C, 2021, 120: 111717

[7] Huang L, Chen J, He M, et al. Nanoparticle structure transformation of $\mathrm{mPEG}$ grafted chitosan with rigid backbone induced by $\alpha$ cyclodextrin. Chinese Chemical Letters, 2019, 30(1): 163-166

[8] Zoya I, He H, Wang L, et al. The intragastrointestinal fate of paclitaxel-loaded micelles: Implications on oral drug delivery. Chinese Chemical Letters, 2021, 32(4): 1545-1549

[9] Totten J D, Wongpinyochit T, Seib F P. Silk nanoparticles: Proof of lysosomotropic anticancer drug delivery at single-cell resolution. Journal of Drug Targeting, 2017, 25(9-10): 865-872

[10] Patiño-Herrera R, Louvier-Hernández J F, Escamilla-Silva E M, et al. Prolonged release of metformin by $\mathrm{SiO}_{2}$ nanoparticles pellets for type II diabetes control. European Journal of Pharmaceutical Sciences, 2019, 131: 1-8

[11] Li Y, Lim E, Fields T, et al. Improving sensitivity and specificity of amyloid- $\beta$ peptides and tau protein detection with antibiofouling magnetic nanoparticles for liquid biopsy of Alzheimer's disease. ACS Biomaterials Science \& Engineering, 2019, 5(7): 3595-3605

[12] D'Mello S R, Cruz C N, Chen M L, et al. The evolving landscape of drug products containing nanomaterials in the United States. Nature Nanotechnology, 2017, 12(6): 523-529

[13] Qi J, Hu X, Dong X, et al. Towards more accurate bioimaging of drug nanocarriers: Turning aggregation-caused quenching into a useful tool. Advanced Drug Delivery Reviews, 2019, 143: 206225

[14] Tosi G, Musumeci T, Ruozi B, et al. The "fate" of polymeric and lipid nanoparticles for brain delivery and targeting: Strategies and mechanism of blood-brain barrier crossing and trafficking into the central nervous system. Journal of Drug Delivery Science and Technology, 2016, 32: 66-76

[15] Chen D, Ganesh S, Wang W, et al. Protein corona-enabled systemic delivery and targeting of nanoparticles. The AAPS Journal, 2020, 22(4): 83

[16] Mekseriwattana W, Srisuk S, Kriangsaksri R, et al. The impact of serum proteins and surface chemistry on magnetic nanoparticle colloidal stability and cellular uptake in breast cancer cells. AAPS PharmSciTech, 2019, 20(2): 55

[17] Srivastav A K, Dhiman N, Khan H, et al. Impact of surfaceengineered $\mathrm{ZnO}$ nanoparticles on protein corona configuration and their interactions with biological system. Journal of Pharmaceutical Sciences, 2019, 108(5): 1872-1889

[18] Yu J, Choi S J. Particle size and biological fate of $\mathrm{ZnO}$ do not cause acute toxicity, but affect toxicokinetics and gene expression profiles in the rat livers after oral administration. International Journal of Molecular Sciences, 2021, 22(4): 1698

[19] Quagliarini E, Di Santo R, Palchetti S, et al. Effect of protein corona on the transfection efficiency of lipid-coated graphene oxide-based cell transfection reagents. Pharmaceutics, 2020, 12 (2): 113

[20] Guo M, Zhao L, Liu J, et al. The underlying function and structural organization of the intracellular protein corona on graphdiyne oxide nanosheet for local immunomodulation. Nano Letters, 2021, 21(14): 6005-6013

[21] Lu X, Xu P, Ding H M, et al. Tailoring the component of protein corona via simple chemistry. Nature Communications, 2019, 10 (1): 4520

[22] Yang Q, Wang M, Sun Y, et al. Pre-incubated with BSAcomplexed free fatty acids alters ER stress/autophagic gene 
expression by carboxylated multi-walled carbon nanotube exposure in THP-1 macrophages. Chinese Chemical Letters, 2019, 30 (6): $1224-1228$

[23] Berrecoso G, Crecente-Campo J, Alonso M J. Unveiling the pitfalls of the protein corona of polymeric drug nanocarriers. Drug Delivery and Translational Research, 2020, 10(3): 730-750

[24] Bertrand N, Grenier P, Mahmoudi M, et al. Mechanistic understanding of in vivo protein corona formation on polymeric nanoparticles and impact on pharmacokinetics. Nature Communications, 2017, 8(1): 777

[25] Coreas R, Cao X, DeLoid G M, et al. Lipid and protein corona of food-grade $\mathrm{TiO}_{2}$ nanoparticles in simulated gastrointestinal digestion. NanoImpact, 2020, 20: 100272

[26] Salatin S, Maleki Dizaj S, Yari Khosroushahi A. Effect of the surface modification, size, and shape on cellular uptake of nanoparticles. Cell Biology International, 2015, 39(8): 881-890

[27] Ban Z, Yuan P, Yu F, et al. Machine learning predicts the functional composition of the protein corona and the cellular recognition of nanoparticles. Proceedings of the National Academy of Sciences of the United States of America, 2020, 117(19): 10492-10499

[28] Escamilla-Rivera V, Uribe-Ramírez M, González-Pozos S, et al. Protein corona acts as a protective shield against $\mathrm{Fe}_{3} \mathrm{O}_{4}$-PEG inflammation and ROS-induced toxicity in human macrophages. Toxicology Letters, 2016, 240(1): 172-184

[29] Gunawan C, Lim M, Marquis C P, et al. Nanoparticle-protein corona complexes govern the biological fates and functions of nanoparticles. Journal of Materials Chemistry B: Materials for Biology and Medicine, 2014, 2(15): 2060-2083

[30] Abstiens K, Maslanka Figueroa S, Gregoritza M, et al. Interaction of functionalized nanoparticles with serum proteins and its impact on colloidal stability and cargo leaching. Soft Matter, 2019, 15(4): 709-720

[31] Cedervall $\mathrm{T}$, Lynch I, Lindman S, et al. Understanding the nanoparticle-protein corona using methods to quantify exchange rates and affinities of proteins for nanoparticles. Proceedings of the National Academy of Sciences of the United States of America, 2007, 104(7): 2050-2055

[32] Caracciolo G. Liposome-protein corona in a physiological environment: Challenges and opportunities for targeted delivery of nanomedicines. Nanomedicine, 2015, 11(3): 543-557

[33] Obst K, Yealland G, Balzus B, et al. Protein corona formation on colloidal polymeric nanoparticles and polymeric nanogels: Impact on cellular uptake, toxicity, immunogenicity, and drug release properties. Biomacromolecules, 2017, 18(6): 1762-1771

[34] Wu R, Peng H, Zhu J J, et al. Attaching DNA to gold nanoparticles with a protein corona. Frontiers in Chemistry, 2020, 8: 121

[35] Givens B E, Wilson E, Fiegel J. The effect of salts in aqueous media on the formation of the $\mathrm{BSA}$ corona on $\mathrm{SiO}_{2}$ nanoparticles. Colloids and Surfaces B: Biointerfaces, 2019, 179: 374-381

[36] Hajipour M J, Raheb J, Akhavan O, et al. Personalized diseasespecific protein corona influences the therapeutic impact of graphene oxide. Nanoscale, 2015, 7(19): 8978-8994

[37] Mo J, Xu Y, Wang X, et al. Exploiting the protein corona: Coating of black phosphorus nanosheets enables macrophage polarization via calcium influx. Nanoscale, 2020, 12(3): 1742-1748

[38] Perng W, Palui G, Wang W, et al. Elucidating the role of surface coating in the promotion or prevention of protein corona around quantum dots. Bioconjugate Chemistry, 2019, 30(9): 2469-2480

[39] Lynch I, Cedervall T, Lundqvist M, et al. The nanoparticle-protein complex as a biological entity; a complex fluids and surface science challenge for the 21st century. Advances in Colloid and Interface Science, 2007, 134-135: 167-174

[40] Hafeez D M, Jalal S, Khosa F. Bibliometric analysis of manuscript characteristics that influence citations: A comparison of six major psychiatry journals. Journal of Psychiatric Research, 2019, 108: 90-94

[41] Yu Y, Li Y, Zhang Z, et al. A bibliometric analysis using VOSviewer of publications on COVID-19. Annals of Translational Medicine, 2020, 8(13): 816

[42] Zhang T, Yin X, Yang X, et al. Research trends on the relationship between Microbiota and Gastric Cancer: A Bibliometric Analysis from 2000 to 2019. Journal of Cancer, 2020, 11(16): 4823-4831

[43] Liu Q, Ye Y. A study on mining bibliographic records by designed software SATI: Case study on library and information science. Journal of Information Resources Management, 2012, 2(1): 50-58 (in Chinese)

[44] Zhou S, Tao Z, Zhu Y, et al. Mapping theme trends and recognizing hot spots in postmenopausal osteoporosis research: A bibliometric analysis. PeerJ, 2019, 7: e8145

[45] Lynch I, Salvati A, Dawson K A. Protein-nanoparticle interactions: What does the cell see? Nature Nanotechnology, 2009, 4(9): 546-547

[46] Röcker C, Pötzl M, Zhang F, et al. A quantitative fluorescence study of protein monolayer formation on colloidal nanoparticles. Nature Nanotechnology, 2009, 4(9): 577-580

[47] Digiacomo L, Pozzi D, Palchetti S, et al. Impact of the protein corona on nanomaterial immune response and targeting ability. Wiley Interdisciplinary Reviews: Nanomedicine and Nanobiotechnology, 2020, 12(4): e1615

[48] Lima T, Bernfur K, Vilanova M, et al. Understanding the lipid and protein corona formation on different sized polymeric nanoparticles. Scientific Reports, 2020, 10(1): 1129

[49] Lundqvist M, Stigler J, Elia G, et al. Nanoparticle size and surface properties determine the protein corona with possible implications 
for biological impacts. Proceedings of the National Academy of Sciences of the United States of America, 2008, 105(38): 1426514270

[50] Monopoli M P, Aberg C, Salvati A, et al. Biomolecular coronas provide the biological identity of nanosized materials. Nature Nanotechnology, 2012, 7(12): 779-786

[51] Tenzer S, Docter D, Kuharev J, et al. Rapid formation of plasma protein corona critically affects nanoparticle pathophysiology. Nature Nanotechnology, 2013, 8(10): 772-781

[52] Monopoli M P, Walczyk D, Campbell A, et al. Physical-chemical aspects of protein corona: Relevance to in vitro and in vivo biological impacts of nanoparticles. Journal of the American Chemical Society, 2011, 133(8): 2525-2534

[53] Nel A E, Mädler L, Velegol D, et al. Understanding biophysicochemical interactions at the nano-bio interface. Nature Materials, 2009, 8(7): 543-557

[54] Walkey C D, Chan W C. Understanding and controlling the interaction of nanomaterials with proteins in a physiological environment. Chemical Society Reviews, 2012, 41(7): 2780-2799

[55] Lesniak A, Fenaroli F, Monopoli M P, et al. Effects of the presence or absence of a protein corona on silica nanoparticle uptake and impact on cells. ACS Nano, 2012, 6(7): 5845-5857
[56] Salvati A, Pitek A S, Monopoli M P, et al. Transferrinfunctionalized nanoparticles lose their targeting capabilities when a biomolecule corona adsorbs on the surface. Nature Nanotechnology, 2013, 8(2): 137-143

[57] Walczyk D, Bombelli F B, Monopoli M P, et al. What the cell "sees" in bionanoscience. Journal of the American Chemical Society, 2010, 132(16): 5761-5768

[58] Boyack K W, Klavans R. Co-citation analysis, bibliographic coupling, and direct citation: Which citation approach represents the research front most accurately? Journal of the American Society for Information Science and Technology, 2010, 61(12): 2389-2404

[59] Wang B, Xing D, Zhu Y, et al. The state of exosomes research: A global visualized analysis. BioMed Research International, 2019, 2019: 1495130

[60] Fan Y, Chen H, Huang Z, et al. Taste-masking and colloidal-stable cubosomes loaded with Cefpodoxime proxetil for pediatric oral delivery. International Journal of Pharmaceutics, 2020, 575: 118875

[61] Dal Magro R, Albertini B, Beretta S, et al. Artificial apolipoprotein corona enables nanoparticle brain targeting. Nanomedicine, 2018, 14(2): 429-438

\section{Supplementary information}

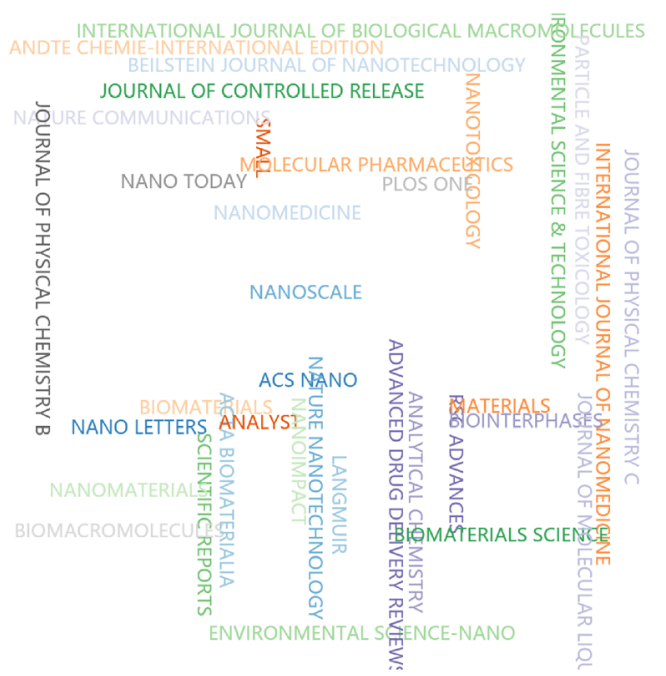

Fig. S1 Word cloud of the distribution of periodicals $(n=1417)$.

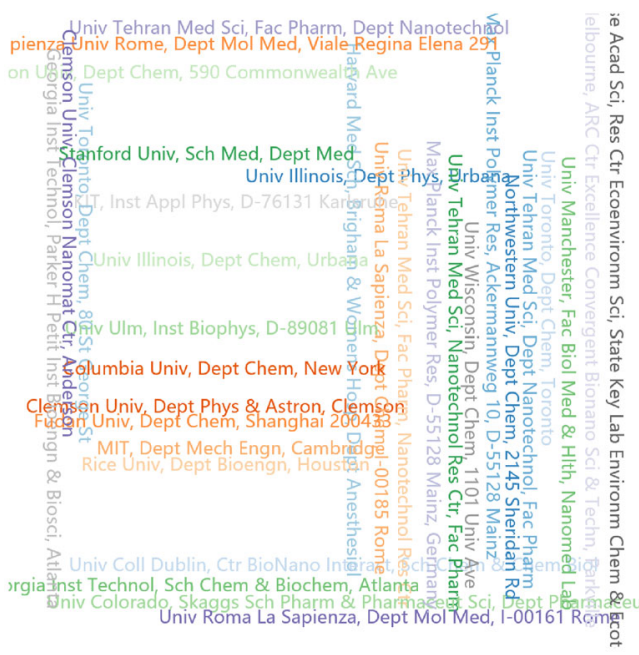

Fig. S2 Word cloud of the distribution of institutions $(n=1417)$. 


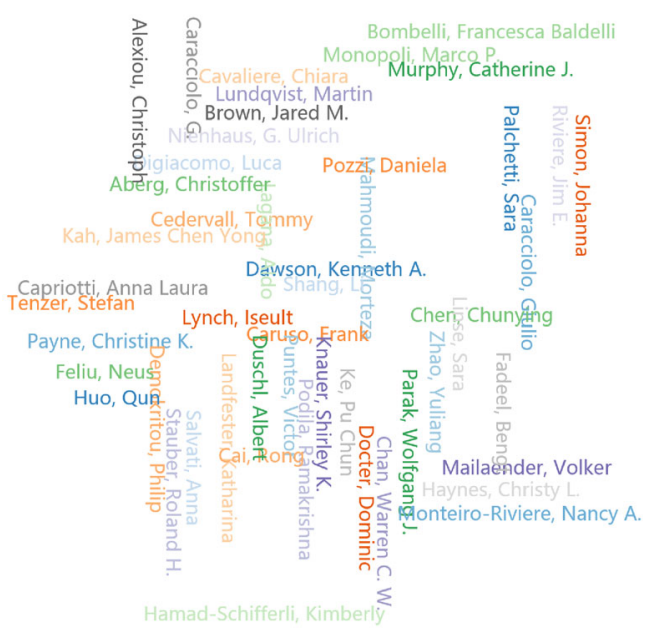

Fig. S3 Word cloud of the distribution of authors $(n=1417)$.

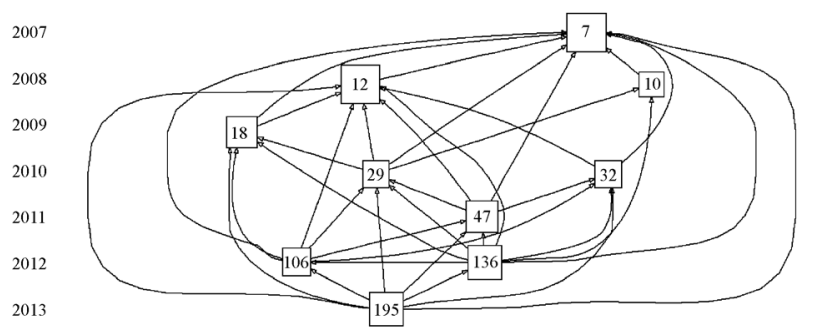

Fig. S4 Cross-citation analysis $(n=1417)$. The assignment of each code is as follows (' $\mathrm{V}$ ' represents volume, ' $\mathrm{P}$ ' represents page, 'LCS' represents local citation score, and 'GCS' represents global citation score): 7 - Cedervall T, 2007, P NATL ACAD SCI USA, V104, P2050 (LCS $=519$, GCS $=1961) ; 10-$ Lynch I, 2008, NANO TODAY, V3, P40 $(\mathrm{LCS}=211, \mathrm{GCS}=1277)$; 12 - Lundqvist M, 2008, P NATL ACAD SCI USA, V105, P14265 $(\mathrm{LCS}=517, \mathrm{GCS}=1932) ; 18-\mathrm{Nel} \mathrm{A} \mathrm{E,} \mathrm{2009,} \mathrm{NAT}$ MATER, V8, P543 $($ LCS $=332$, GCS $=4433) ; 29-$ Walczyk D, 2010, J AM CHEM SOC, V132, P5761 ( $\mathrm{LCS}=248$, GCS = 830); 32 - Casals E, 2010, ACS NANO, V4, P3623 (LCS $=242$, GCS = 757); 47 - Monopoli M P, 2011, J AM CHEM SOC, V133, P2525 $(\mathrm{LCS}=345, \mathrm{GCS}=1173) ; 106$ - Lesniak A, 2012, ACS NANO, V6, P5845 $($ LCS = 274, GCS = 682); 136 - Monopoli M $\mathrm{P}, 2012$, NAT NANOTECHNOL, V7, P779 $(\mathrm{LCS}=397, \mathrm{GCS}=$ 1511); 195 - Tenzer S, 2013, NAT NANOTECHNOL, V8, P772 $(\mathrm{LCS}=389, \mathrm{GCS}=1182)$.

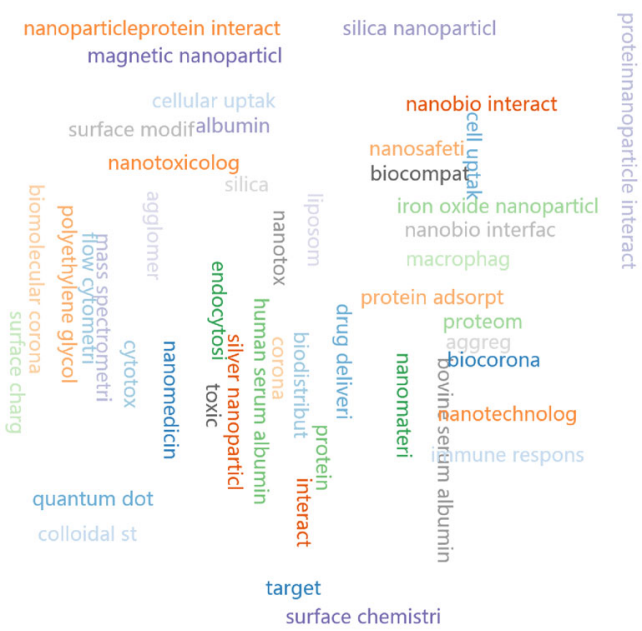

Fig. S5 Word cloud of the profile of keywords $(n=1417)$.

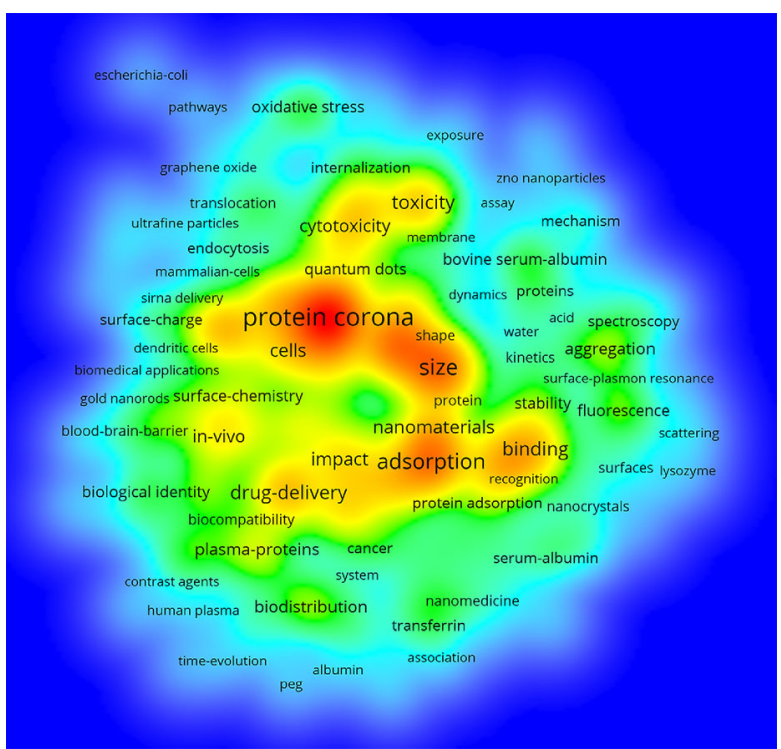

Fig. S6 Density visualization of high-frequency keywords $(n=$ 1417). 